\title{
Article \\ The Modulation of Auxin-Responsive Genes, Phytohormone Profile, and Metabolomic Signature in Leaves of Tomato Cuttings Is Specifically Modulated by Different Protein Hydrolysates
}

\author{
Valentina Buffagni ${ }^{1,+}{ }^{\dagger}$, Angela Valentina Ceccarelli ${ }^{2,+}$, Youry Pii ${ }^{3, *} \mathbb{D}$, Begoña Miras-Moreno ${ }^{1}$, \\ Youssef Rouphael ${ }^{4}$ (D), Mariateresa Cardarelli ${ }^{5}\left(\mathbb{D}\right.$, Giuseppe Colla $^{2}$ and Luigi Lucini ${ }^{1}$ (D) \\ 1 Department for Sustainable Food Process-DiSTAS, Università Cattolica del Sacro Cuore, \\ Via Emilia Parmense 84, 29122 Piacenza, Italy; valentina.buffagni@unicatt.it (V.B.); \\ mariabegona.mirasmoreno@unicatt.it (B.M.-M.); luigi.lucini@unicatt.it (L.L.) \\ 2 Department of Agriculture and Forest Sciences, University of Tuscia, 01100 Viterbo, Italy; \\ avceccarelli@unitus.it (A.V.C.); giucolla@unitus.it (G.C.) \\ 3 Faculty of Science and Technology, Free University of Bozen, Piazza Università, 5, 39100 Bolzano, Italy \\ 4 Department of Agricultural Sciences, University of Naples Federico II, Via Università 100, 80055 Portici, Italy; \\ youssef.rouphael@unina.it \\ check for \\ updates \\ Citation: Buffagni, V.; Ceccarelli, \\ A.V.; Pii, Y.; Miras-Moreno, B.; \\ Rouphael, Y.; Cardarelli, M.; Colla, G.; \\ 5 Consiglio per la Ricerca in Agricoltura e l'analisi Dell'economia Agraria, \\ Centro di Ricerca Orticoltura e Florovivaismo, Via Cavalleggeri, 25, 84098 Pontecagnano Faiano, Italy; \\ mteresa.cardarelli@crea.gov.it \\ * Correspondence: youry.pii@unibz.it; Tel.: +30-0471-017164 \\ + These authors contributed equally.
}

Lucini, L. The Modulation of

Auxin-Responsive Genes,

Phytohormone Profile, and

Metabolomic Signature in Leaves of

Tomato Cuttings Is Specifically

Modulated by Different Protein

Hydrolysates. Agronomy 2021, 11,

1524. https://doi.org/10.3390/

agronomy11081524

Academic Editor:

Dionisios Gasparatos

Received: 10 June 2021

Accepted: 29 July 2021

Published: 30 July 2021

Publisher's Note: MDPI stays neutral with regard to jurisdictional claims in published maps and institutional affiliations.

Copyright: (c) 2021 by the authors. Licensee MDPI, Basel, Switzerland. This article is an open access article distributed under the terms and conditions of the Creative Commons Attribution (CC BY) license (https:// creativecommons.org/licenses/by/ $4.0 /)$.
Abstract: Protein hydrolysates (PHs) are employed in agriculture to increase the sustainability of farming systems, with positive results on crop productivity and response against environmental stressors. Nevertheless, the molecular mechanism(s) triggered by their specific activity is not clearly understood. In this work, five PHs obtained by enzymatic hydrolysis of different vegetal protein sources were tested for their root-promoting activity on tomato cuttings. All the treatments improved both root length and number when compared to negative controls. Distinctive metabolomic signatures were highlighted in response to treatments, indicating the triggering of different molecular processes in leaf tissues of tomato cuttings. PHs differentially modulated the biosynthesis of plant stress-protectants, such as alkaloids and phenylpropanoids. Moreover, metabolites involved in phytohormone biosynthesis were significantly impacted. In this context, a clear modulation of several compounds related to auxin homeostasis was observed. In addition, the differential modulation of SIIAA2 and SIIAA9 genes, which are involved in the IAA signalling pathway, might further suggest the auxin-like activity elicited by the PHs tested. Here we provide evidence that PHs can impact plant molecular level, positively affecting root development, most likely by affecting the signalling cascades activated in leaf tissues. The biostimulant activity was sustained by PH-specific response at the molecular level, likely ascribable to their heterogeneous botanical origins. In fact, our findings did not point out a clear universal response to $\mathrm{PHs}$, and specific effects are to be investigated.

Keywords: biostimulants; protein hydrolysates; plant signalling; auxin bio-assay; Aux/IAA transcription factors; gene expression; rooting

\section{Introduction}

In recent years, the demand for food has dramatically increased in terms of both quality and quantity to meet the need of the increasing world population, which is expected to reach 9 billion people by 2050 [1]. To date, the enhancement in agricultural productivity has been mainly achieved by increasing the supplementation of agrochemicals, aimed at both boosting crop yield and protecting them from diseases that could lead to losses in 
production [2]. However, arable resources are decreasing due to both soil degradation and climate change, and the nonrenewable natural resources used for the production of fertilizers (e.g., rock phosphate) are limited and are expected to be consumed in the near future $[3,4]$. On these bases, agricultural practice is required to move towards more sustainable approaches, which should progressively be less dependent on the application of external inputs. In this context, plant biostimulants $(\mathrm{PB})$ are envisaged as substances able to improve both crop productivity and yield, to foster the bioavailability of nutrients in the soil, and to affect soil fertility by promoting the degradation and humification of organic substances [5,6]. Interestingly, biostimulants were first defined as molecules that, when applied in small amounts, could promote plant growth, thus setting a clear distinction with agrochemicals that are generally supplemented in larger quantities [7]. Several definitions for biostimulants have been proposed over time, stating that the primary function of PBs is not to provide nutrients, or target pests and pathogens, but to enhance crop quality, to ameliorate plants' nutrient use efficiency, increase their resistance to stress, and improve plant productivity for their complex and variegate composition, as a consequence of novel or emergent properties [8,9]. At present, the European Biostimulants Industry Council (EBIC) has defined as biostimulants any "substance(s) and/or micro-organisms whose function, when applied to plants or the rhizosphere, is to stimulate natural processes to enhance/benefit nutrient uptake, nutrient efficiency, tolerance to abiotic stress, and crop quality" (https: / / eurlex.europa.eu/eli/reg/2019/1009/oj, accessed on 24 March 2020). Indeed, PBs can be obtained from a wide variety of sources, to include protein hydrolysates (PHs), humic and fulvic substances, seaweed extracts, animal and vegetal protein extracts, beneficial microorganisms, arbuscular mycorrhizal fungi and nitrogen-fixing bacteria belonging to Rhizobium, Azotobacter and Azospirillum [6].

PHs obtained from the enzymatic hydrolysis of vegetal-derived proteins are receiving great interest as plant biostimulants due to the high agronomic efficacy and the environmentally-sound production process [10,11]. Biostimulant activity of PHs can be related to the hormone-like activity of bioactive components such as signalling peptides and amino acids [12]. Auxin and gibberellin-like activity have been detected in PHs using bioassays such as rooting of tomato cuttings and the lettuce hypocotyl elongation test, respectively [12,13]. In this context, the phytohormone auxin has been widely demonstrated to play a pivotal role in many aspects of plants developmental processes, particularly controlling both shoot and root growth and architecture [14]. Such control on morphogenetic processes can be achieved by differential auxin concentrations within plant tissues (i.e., gradients, maxima and minima), which is the result of a tight and coordinated control of auxin biosynthesis, transport and conjugation/inactivation [15]. At cell level, the auxin responses to specific physiological and environmental stimuli are mediated by the modulation of transcription factors and effectors of the epigenetic machinery that regulates the expression of auxin-responsive genes [15].

The understanding of PHs mode of action in plants have been recently boosted by the exploitation of both metabolomics and transcriptomics, which have been proven to be powerful tools to this purpose $[16,17]$. However, to the best of our knowledge, the combined exploitation of different omics techniques aimed at identifying gene(s)-metabolite(s) relationships specific to phenotypes has never been applied in plant biostimulant studies. Starting from these considerations, the aim of the study was to explore the possibility of linking bio-assays (i.e., rooting tests) and metabolomics data with the expression of target genes involved in the signalling pathways of phytohormones at the leaf level with specific reference to auxin, considering its pivotal role in regulating root system growth and architecture in plants $[18,19]$. To this objective, tomato cuttings were treated at the leaf level with five PHs (i.e., PH2, PH3, PH4, PH6 and PH10), from different botanical origins, and hence having different compositions. After 1 week, cuttings were assessed for the development of roots (being an index for auxin-like activity [20]), and, at the molecular level, for the profile of metabolites and for modulation of selected key genes involved in the auxin transduction pathway. 


\section{Materials and Methods}

\subsection{Plant Material and Auxin-Like Activity Bioassays}

Seeds of tomato (Solanum lycopersicum L.) cv. Akrai F1, (SAIS Sementi, Cesena, Italy) were surface-sterilized with $2 \%$ sodium hypochlorite for $20 \mathrm{~min}$ then washed with distilled water, sown in a germination tray filled with a commercial peat moss-based substrate (Brill, Gebr. Brill Substrate GmbH \& Co., Georgsdorf, Germany) and placed in a growth chamber under controlled conditions (photoperiod $12 \mathrm{~h}$, light intensity was set to $450 \mu \mathrm{mol} \mathrm{m}^{-2} \mathrm{~s}^{-1}$, the temperature was kept at $24{ }^{\circ} \mathrm{C}$ and the relative humidity constantly maintained at $70 \%$ ). At 15 days after germination, the root system was removed through an excision $1 \mathrm{~cm}$ above the soil line. The explants were treated with five different protein hydrolysates (i.e., PH2, PH3, PH4, PH6 and PH10), previously characterized [21], at a concentration of $8 \mathrm{~g} \mathrm{~L}^{-1}$. Positive controls were obtained by treating explants with indol-3-acetic acid (IAA) at $0.1,0.5$ and $1 \mathrm{mM}$, whilst the negative control was represented by explants treated with distilled water. The treatments were carried out by rapidly soaking (for $3 \mathrm{~s}$ ) tomato leaves in the designated solutions [22] and, soon after, by placing the explants into polypropylene microboxes (diameter $90 \mathrm{~mm}$, height $140 \mathrm{~mm}$ ) containing a $50 \mathrm{~mm}$ layer of wetted quartziferous sand. The microboxes were closed with parafilm to ensure relative humidity close to saturation (100\%). Treatments were arranged in a completely randomized block design with three replicates; each experimental unit consisted of a microbox containing five cuttings. Plant material was sampled 7 days after the treatments. At harvest, the morphology of the root system (i.e., root length and number of roots) was assessed by scanning the root system using an Epson Perfection V700 Photo scanner. The images were then processed through WinRHIZO (Regent Instrument Inc., Quebec, QC, Canada) software to determine total root length and number. In addition, roots and shoots were separated, immediately frozen in liquid nitrogen and stored at $-80{ }^{\circ} \mathrm{C}$ until further analyses.

\subsection{Gene Expression Analysis}

RNA samples were extracted from the shoot tissue of plants used for auxin-like activity bioassays. Total RNA was isolated using a Spectrum Plant Total RNA Kit (Sigma-Aldrich Co. LLC, St. Louis, MO, USA) according to the operating manual. Afterwards, $1 \mu \mathrm{g}$ of total RNA was treated with $10 \mathrm{U}$ of DNAse RQ1, and cDNA was synthesized using the ImProm-II Reverse Transcription System (Promega, Madison, WI, USA). Specific primers for the target genes as well as for the housekeeping genes, were designed and reported in Table S1. Quantitative real-time reverse transcription-PCR (qRT-PCR) was carried out as previously described [23]. The relative expression ratio value was calculated according to the Pfaffl equation [24,25].

\subsection{Metabolomic Analysis}

Shoots from five cuttings per treatment were analyzed using a UHPLC system coupled to a hybrid quadrupole-time-of-flight mass spectrometer (UHPLC/QTOF-MS) as previously reported [26]. Briefly, shoot samples were extracted using a homogenizer-assisted extraction in $80 \%$ methanol solution acidified with $0.1 \%(v / v)$ formic acid. The extracts were centrifuged and filtered through $0.22 \mu \mathrm{m}$ cellulose syringe filters in amber glass vials for analysis. Metabolomic analysis was carried out through UHPLC liquid chromatography quadrupole-time-of-flight mass spectrometry (UHPLC/QTOF-MS). A water-acetonitrile gradient elution (6\% to $94 \%$ acetonitrile in $34 \mathrm{~min}$ ) on an Agilent Zorbax Eclipse Plus C18 column $(50 \mathrm{~mm} \times 2.1 \mathrm{~mm}, 1.8 \mu \mathrm{m})$ and positive polarity SCAN acquisition (range 100-1200 m/z) were used. A JetStream electrospray was used as ionization source, as previously set up [27]. The sequence injection was randomized, and blank samples (extraction solvent only) injected at the beginning and at the end of the sequence. Quality control samples (QCs) were randomly analyzed throughout the sequence using the same chromatographic method but in a data-dependent MS/MS mode (10 precursors per cycle, $1 \mathrm{~Hz}, 50-1200 \mathrm{~m} / \mathrm{z}$, active exclusion after two spectra), with collision energies of 10, 20 and 
$40 \mathrm{eV}$ for collision-induced decomposition [28]. QCs were used to increase confidence in the annotation.

The raw mass features were processed according to a targeted 'find-by-formula' algorithm by the Agilent Profinder B.06 (Agilent Technologies) software. In particular, the isotopic pattern (monoisotopic mass and isotopes profile), adopting a mass tolerance of 5-ppm, was applied following mass and retention time alignment. For annotation purposes, the comprehensive database PlantCyc 9.6 (Plant Metabolic Network, http:/ /www.plantcyc.org, accessed on 24 March 2020) was used. Therefore, in our untargeted conditions, a Level 2 of annotation (i.e., putatively annotated compounds) was achieved, as reported by COSMOS Metabolomics Standards Initiative [29]. The compounds annotation step was strengthened by processing QCs in MS-DIAL 4.24 [30]. To this aim, both the publicly available MS/MS experimental spectra built in the software (MONA; Mass Bank of North America, Davis, CA, USA) and the MS-Finder in-silico fragmentation spectra from the compounds in PlantCyc [31] were used.

\subsection{Statistical Analyses}

The results are reported as mean \pm standard error (SE) of five independent biological replicates. The significance of differences among means was calculated by one-way ANOVA with post hoc Tukey HSD with $\alpha=0.05$ using R software (version 3.6.0). The following $\mathrm{R}$ packages were used for data visualization and statistical analyses: ggplot2 v.3.2.0 [32], Agricolae v.1.3-1 [33] and ggfortify [34].

Metabolomics data were analyzed through Agilent Technologies Mass Profiler Professional 12.6 as previously described [28]. Compound abundance was $\log 2$ transformed, normalized at 75 th percentile, and baselined against the median. Unsupervised hierarchical cluster analysis (HCA) was used to describe similarity/dissimilarity across treatments (Euclidean distance, Ward's linkage). Thereafter, the dataset was uploaded into Simca+ (Umetrics, Malmo, Sweden) for supervised modelling by orthogonal projection to latent structures discriminant analysis (OPLS-DA). Therein, the model goodness parameters, namely correlations R2X, R2Y and Q2Y prediction ability, were calculated. A Volcano analysis was finally carried out by combining ANOVA $(p<0.01$ Bonferroni multiple testing correction) and fold-change analysis (cut-off $\geq 3$ ), and differential compounds interpreted using the PlantCyc Pathway Tool (https://www.plantcyc.org, accessed on 24 March 2020) [35,36].

\section{Results}

\subsection{Rooting Bioassay}

The rooting tests in tomato seedlings were carried out in order to investigate the IAA-like activity exerted by protein hydrolysates ( $\mathrm{PHs}$ ) administered at a concentration of $8 \mathrm{~g} \mathrm{~L}^{-1}$ and compared with positive and negative controls, i.e., namely tomato seedling treated with indol-3-acetic acid (IAA) and water, respectively. As shown in Figure 1, the treatments significantly affected both the root length and the root number $(p<0.001$ and $p<0.01$, respectively). In particular, concerning the root length parameter, the greatest effect was displayed by the treatment with PH4 and PH10, that almost doubled the extension of the root system of tomato seedlings as compared to the negative control (Figure 1a). Interestingly, the two above-mentioned treatments showed a higher rooting activity even when they were compared to IAA-treated tomato seedlings (Figure 1a). All the other treatments showed intermediate root length values, which were not significantly different from both positive and negative controls and the PHs inducing the highest responses (i.e., PH4 and PH10) (Figure 1a). 
(a)

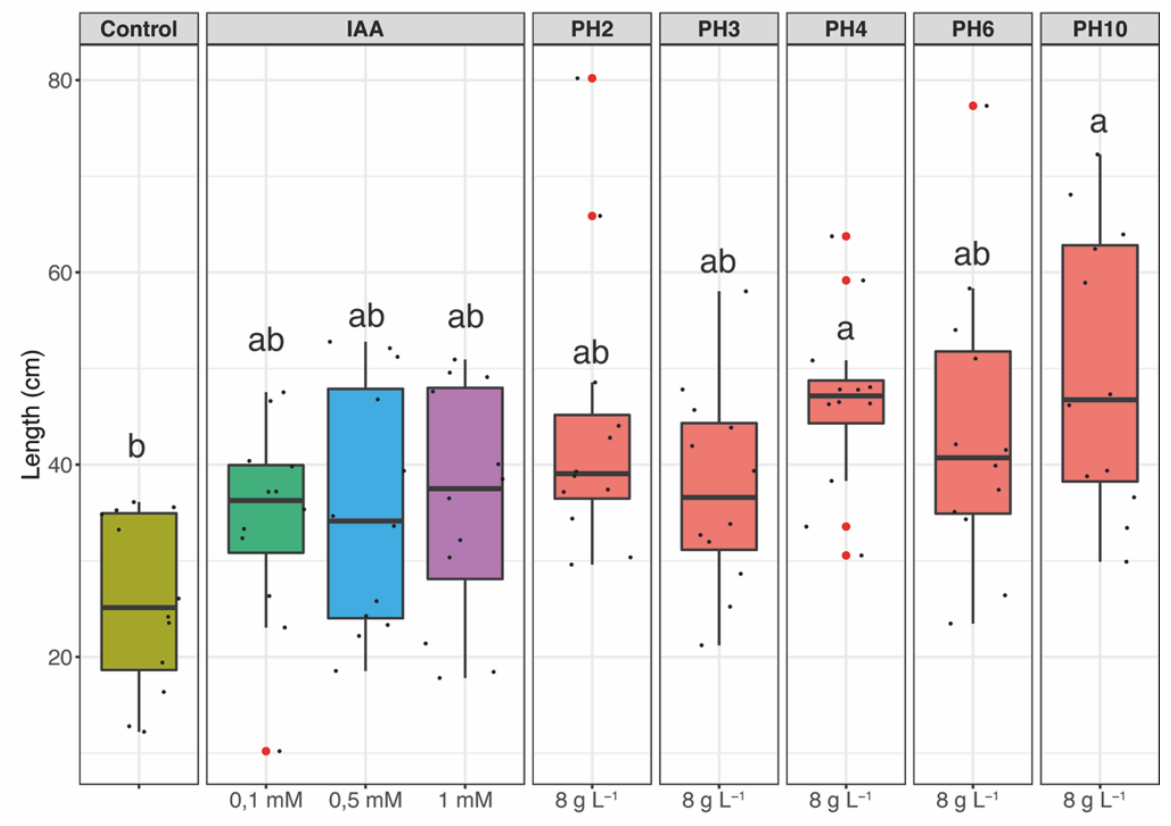

(b)

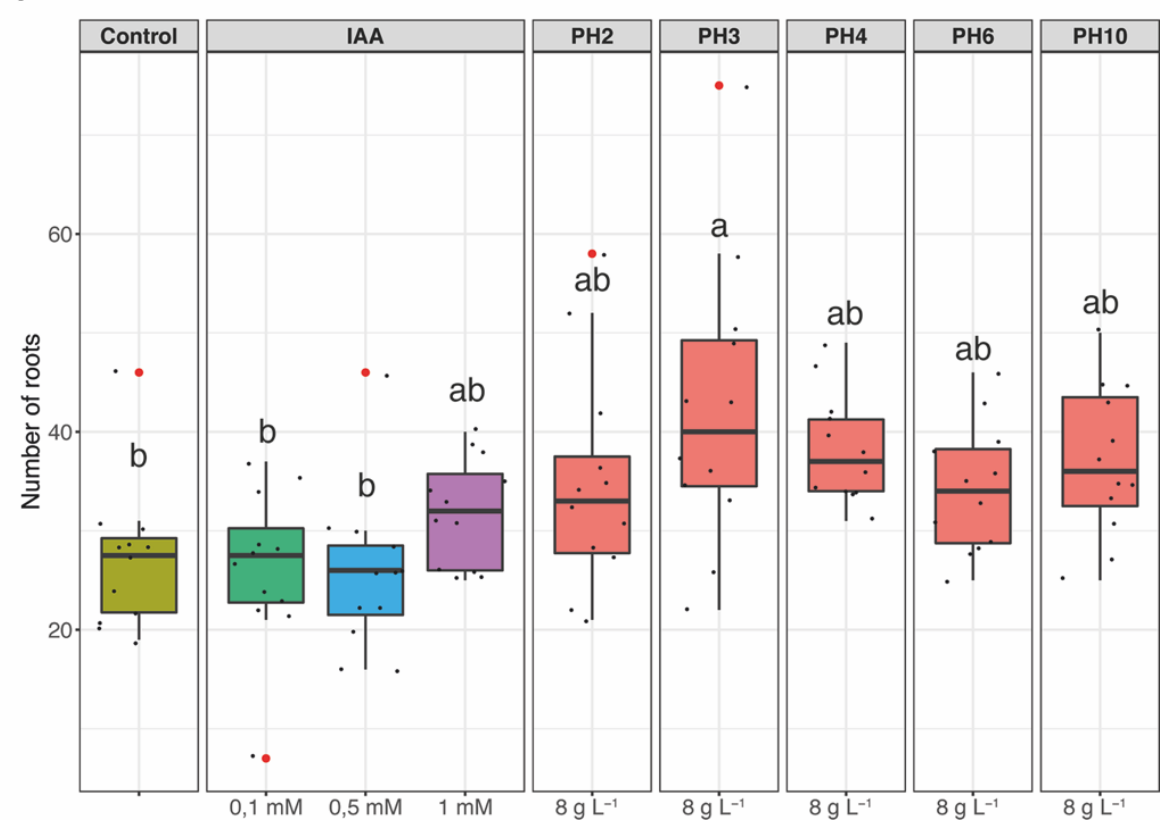

Figure 1. Root growth parameters of tomato plants as affected by different treatments. (a) Total root length and (b) total number of roots determined in tomato cuttings at 7 days after treatments. The analyses were carried out on at least 10 cuttings per each treatment. Different letters indicate significant differences according to one-way ANOVA with Tukey post hoc tests $(p<0.05)$.

When the number of roots was considered, the $\mathrm{PH} 3$ gave the biggest increase as compared to both positive and negative controls, whilst the other PHs tested produced intermediate effects not significantly different from controls (Figure 1b).

\subsection{Effects on IAA Responsive Genes}

To further understand whether the rooting activity exerted by PHs could be ascribable to an IAA-mediated pathway, the expression of two key genes (i.e., SIIAA2 and SIIAA9) involved in the IAA signalling pathway was monitored in the leaves of tomato seedlings 
(Figure 2). In particular, both SIIAA2 and SIIAA9 were previously shown to be responsive to exogenous IAA treatments in tomato leaves, albeit displaying different timing in the response [37].

(a)

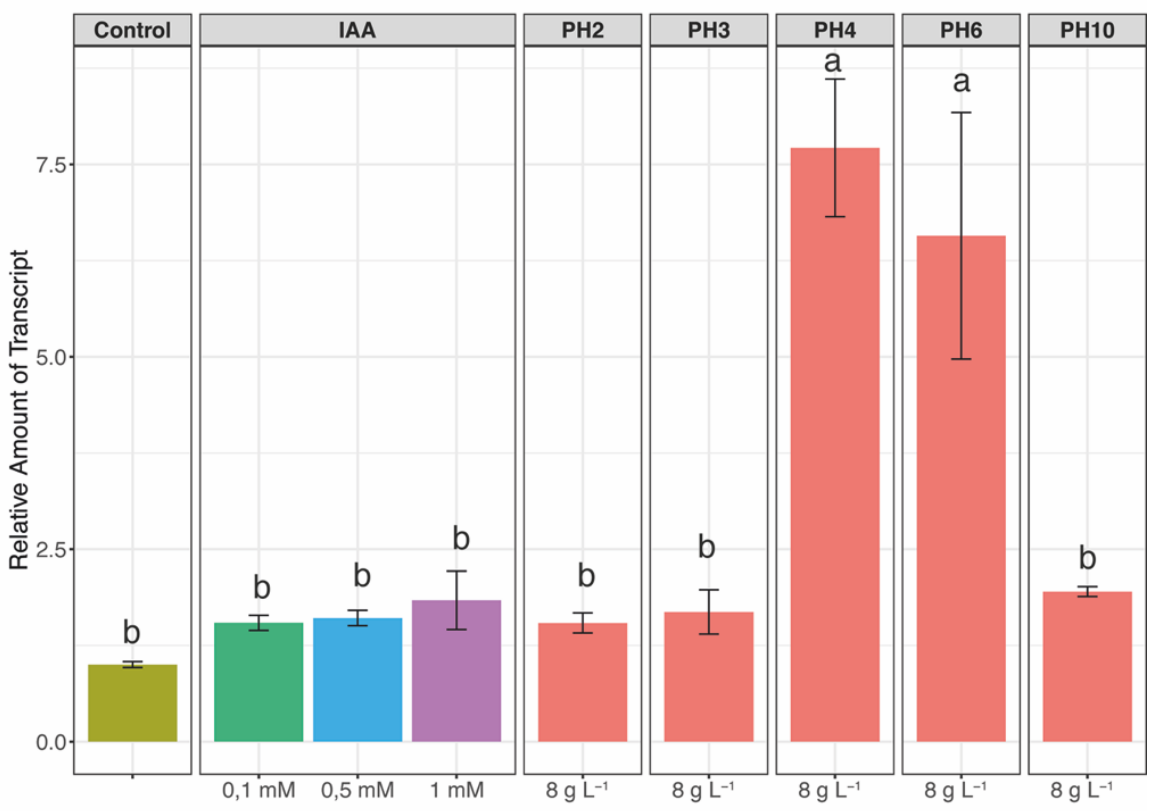

(b)

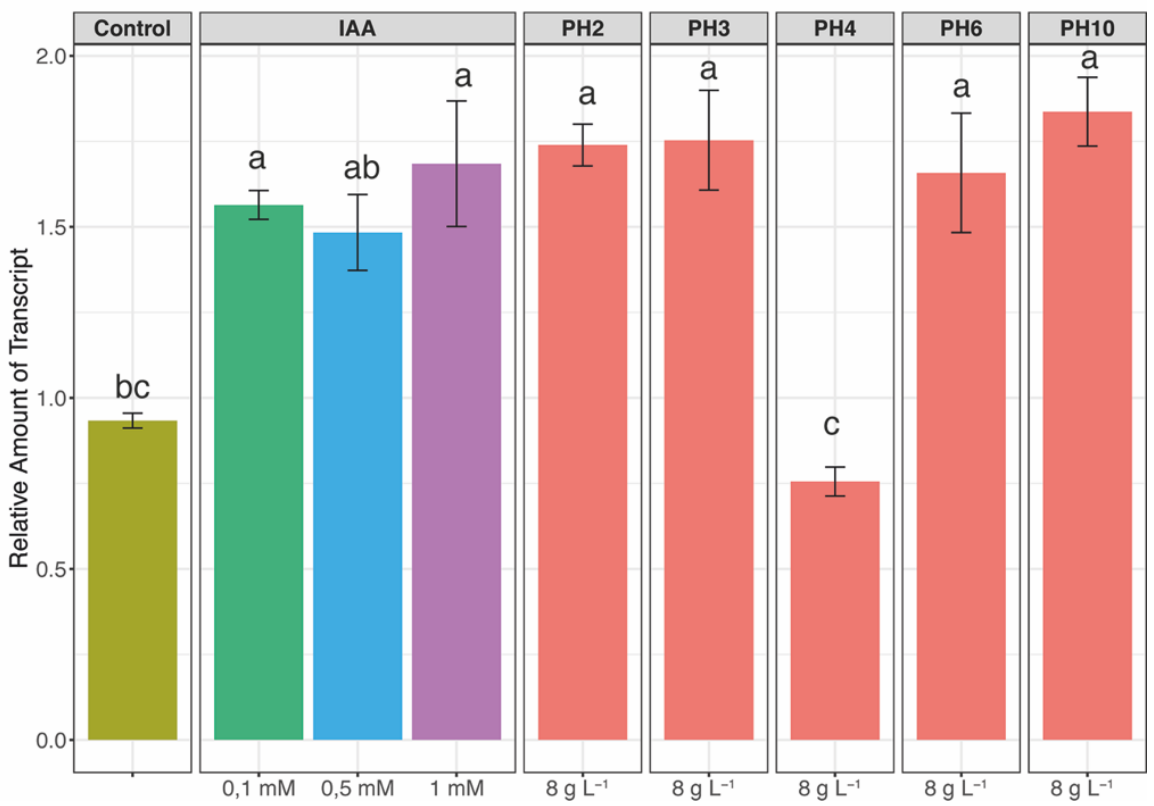

Figure 2. Quantitative RT-PCR analyses of selected IAA-responsive transcription factors. (a) SIIAA2 and (b) SIIAA9. The assessment was carried out on leaf tissue of tomato plants at 7 days after treatments. The data were normalized to the Elongation Factor $1 \alpha$ housekeeping genes. The relative expression ratios were calculated using control plants as a calibrator sample. The values reported are means SE of three biological replicates. Different letters indicate significant differences according to one-way ANOVA with Tukey post hoc tests $(p<0.05)$.

The qRT-PCR analysis carried out on SIIAA2 showed a significant induction only in the leaf tissue of tomato seedlings treated with PH4 and PH6 (Figure 2a). On the other hand, the analysis of SIIAA9 showed that it was significantly induced by the treatments 
with PHs, except for PH4 (Figure 2b). Interestingly, the relative mRNA levels detected in the leaf of PH-treated seedlings were comparable to those obtained from the analysis of $1 \mathrm{mM}$ IAA-treated tomato plants. Noteworthy is that the response of the two genes mainly showed an opposite behaviour upon the different treatments, even to the positive controls (i.e., IAA at different concentration). As pointed out above, SIIAA2 and SIIAA9 were shown to have different timing in the response to exogenous IAA treatments. Considering this, it was expected that SIIAA2 was not modulated following the treatments, and SIIAA9 showed an upregulation with respect to negative controls. Nevertheless, SIIAA2 was unexpectedly induced by PH4 and PH6, whereas SIIAA9 was not modulated by PH4 treatments (Figure 2). Indeed, PHs used in this study were obtained starting from different vegetal matrixes; therefore, they may feature different composition at the molecular level that might differentially impact the signalling cascades in plants.

\subsection{Untargeted Metabolomic Profiling}

A UHPLC/QTOF-MS analysis of tomato leaf extracts was carried out in order to understand the impact of $\mathrm{PH}$ application on the metabolomic profile. For metabolomics analysis we used plants treated with IAA $1 \mathrm{mM}$ as positive controls. Approximately 3000 compounds were obtained, annotated and used for the subsequent statistical analyses (Table S2). The unsupervised hierarchical cluster analysis (HCA), carried out to differentiate the samples according to the variation of metabolites abundance, highlighted two clusters, one featuring PH2, PH4 and PH6, while the other was formed by PH3, PH10, negative and positive controls (Figure 3).

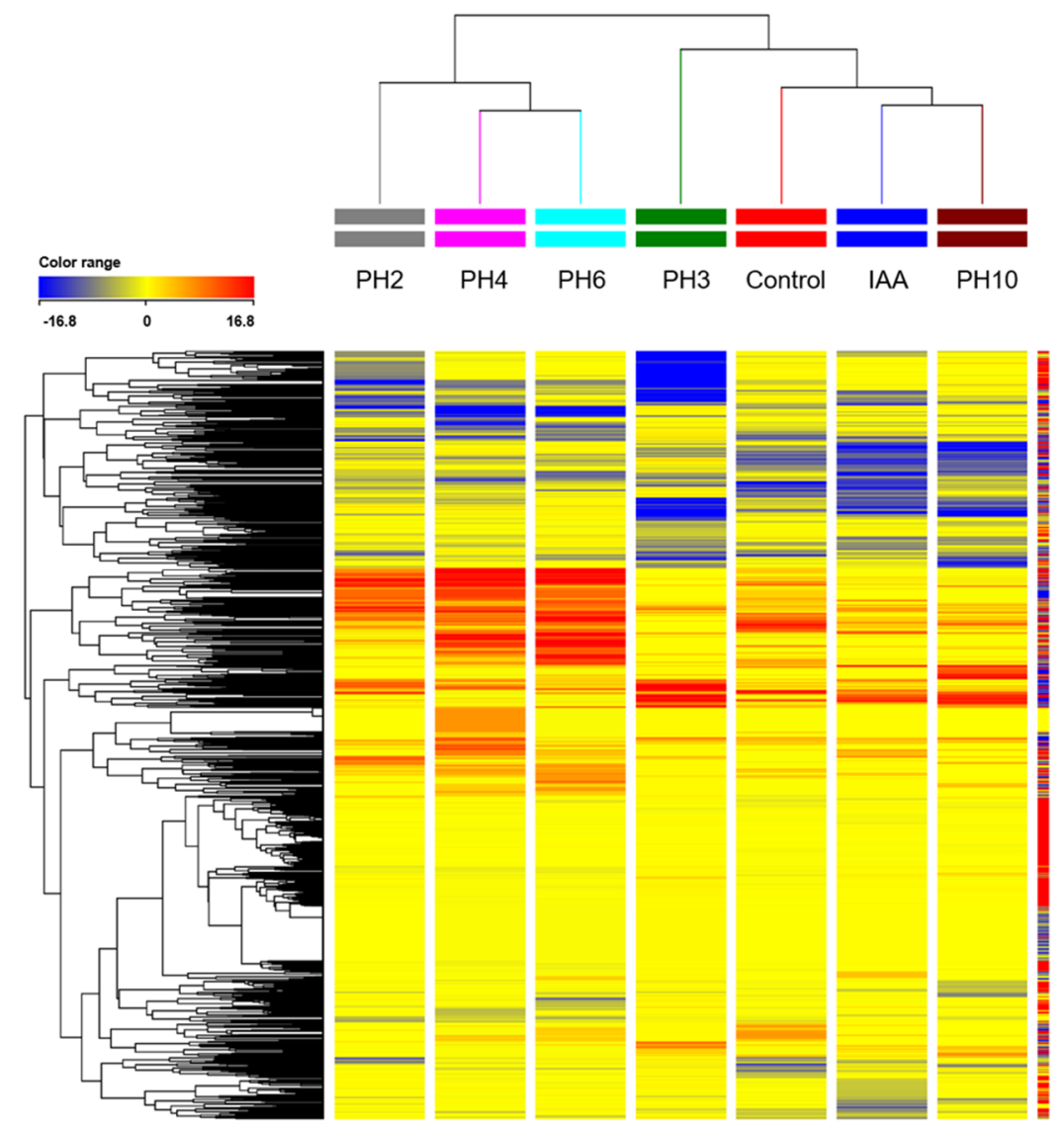

Figure 3. Unsupervised hierarchical cluster analysis (HCA) carried out from UHPLC-ESI/QTOF-MS metabolomics analysis of tomato leaves treated with protein hydrolysate $(\mathrm{PH})$ applications. Indole-3acetic acid (IAA $1 \mathrm{mM}$ ) was used as positive control. The fold-change-based heat map was used to build hierarchical clusters (linkage rule: Ward; distance: Euclidean). 
Such distribution of samples was further confirmed by OPLS-DA (Figure S1). The model was validated by the goodness of fit $(\mathrm{R} 2 \mathrm{Y}>0.88)$, the prediction ability $(\mathrm{Q} 2 \mathrm{Y}>0.5)$, and by the cross-validation analysis of variance CV-ANOVA $p$-value $<0.05$. Consistent with the evidence obtained through HCA, PH2, PH4 and PH6 were distributed independently on the scatter plot, whilst IAA-treated samples and PH10 displayed an overlapping distribution, except for one PH10 replicate outliers that clustered with controls. On the other hand, PH3-treated samples formed a cluster, which was independent from all the other samples (Figure S1). The differentially represented compounds were pointed out by applying a Volcano Plot analysis ( $p$-value $<0.01 ; \mathrm{FC}>3)$, which allowed identifying approximately 350 molecules, subsequently used to understand the impact of $\mathrm{PH}$ treatments on metabolome (Table S3). To further clarify the metabolic processes likely affected by the treatment, a pathway tool analysis from the PlantCyc database was applied and the outcomes are summarized in Figure 4, reporting the biosynthetic processes and the biosynthesis of secondary metabolites, and in Table 1, in which the profiles of metabolites related to hormone pathways are presented.

According to the results obtained, greater modulations were observed in the synthesis of secondary metabolites. Cumulative log FC highlighted an overall suppression of secondary metabolism in response to IAA, PH10 and PH3, this latter being the most effective. On the contrary, PH4 and PH6 elicited secondary pathways, but PH6 induced the strongest effect (Figure $4 \mathrm{a}$ ). These results further confirmed the samples' distribution produced by the OPLS-DA. The main modulations were observed in the group of $\mathrm{N}$-containing compounds and in that of terpenes (Figure $4 \mathrm{~b}$ ). Alkaloids were the most represented $\mathrm{N}$-containing molecules, which were particularly enriched in samples treated with PH6 and PH4 as well as PH2, albeit to a lower extent. By contrast, they were depleted in PH3 and IAA-treated samples. Similarly, terpenes (mono-, di- and tri- terpenoids) were accumulated in PH6 and PH4-treated samples whilst depleted in the leaves of tomato plants supplemented with IAA, PH2 and PH3 (Figure 4b). All treatments influenced hormone biosynthesis, displaying peculiar variations depending on the hydrolysate applied (Table 1). The metabolites involved in the synthesis of abscisic acid, cytokinins and gibberellins displayed an overall decrease with the treatments, whereas PH4 and PH6 induced the accumulation of molecules involved in the synthesis of brassinosteroids and jasmonate (Table 1).

The auxin pathways were differentially affected by treatments. Positive controls accumulated the IAA precursor (indol-3-yl)acetamide to the same extent as all PHs apart from PH10. On the other hand, the storage form of IAA, methyl (indol-3-yl)acetate, significantly decreased in positive controls and in PH3 and PH10-treated plants only. Different conjugated forms of IAA resulted in differential compounds, such as the glucosylated form of the 2-oxoindole-3-acetate (OxIAA-Glc). OxIAA-Glc under-accumulated in response to exogenous application of IAA $(1 \mathrm{mM}), \mathrm{PH} 3, \mathrm{PH} 4$ and PH6. The ethylene precursor 1-aminocyclopropane-1-carboxylate (ACC) was slightly modulated by treatments. In particular, only PH3 and PH10 mimicked the similar accumulation (Log FC up to 2-fold) of ACC observed in positive controls. 
(a)

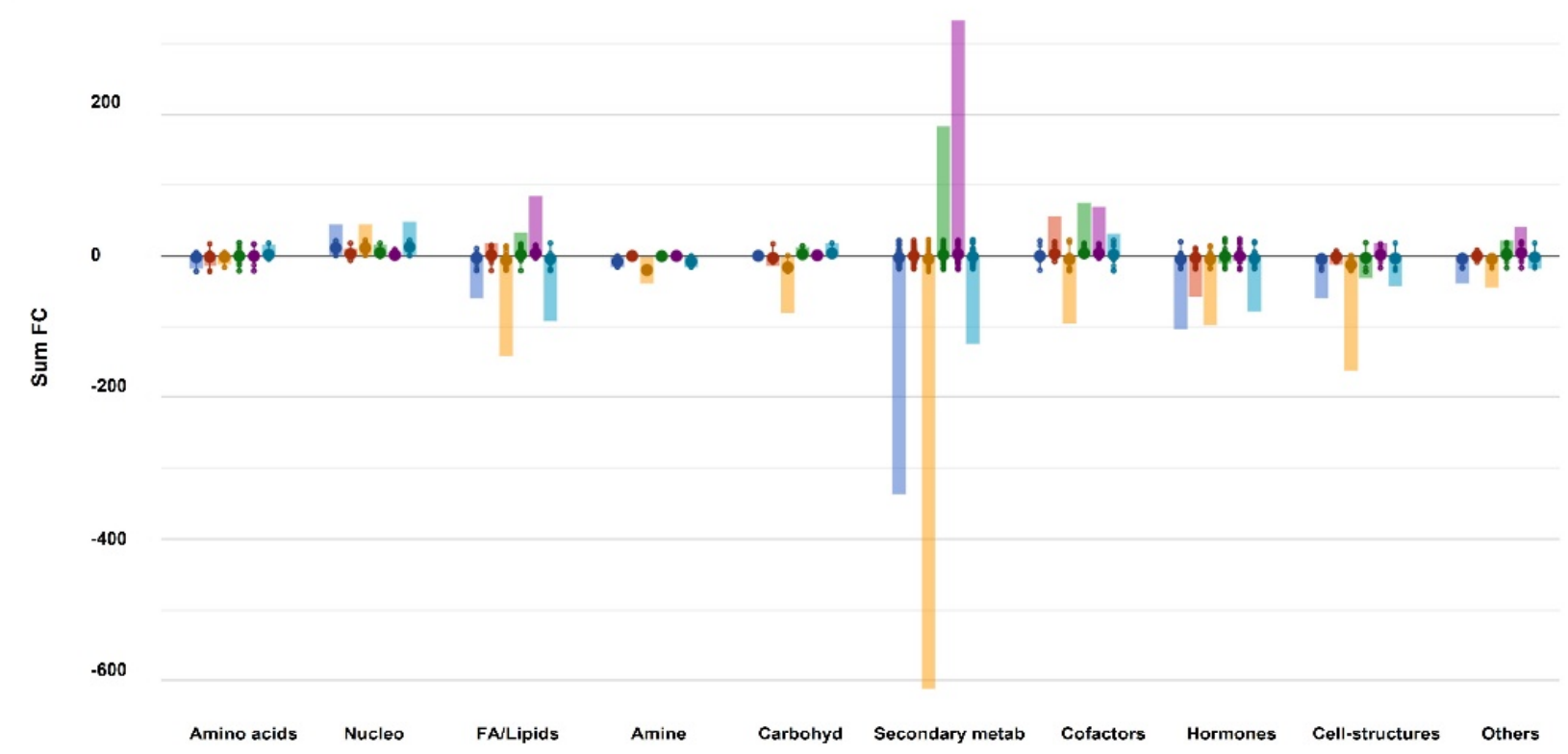

(b)

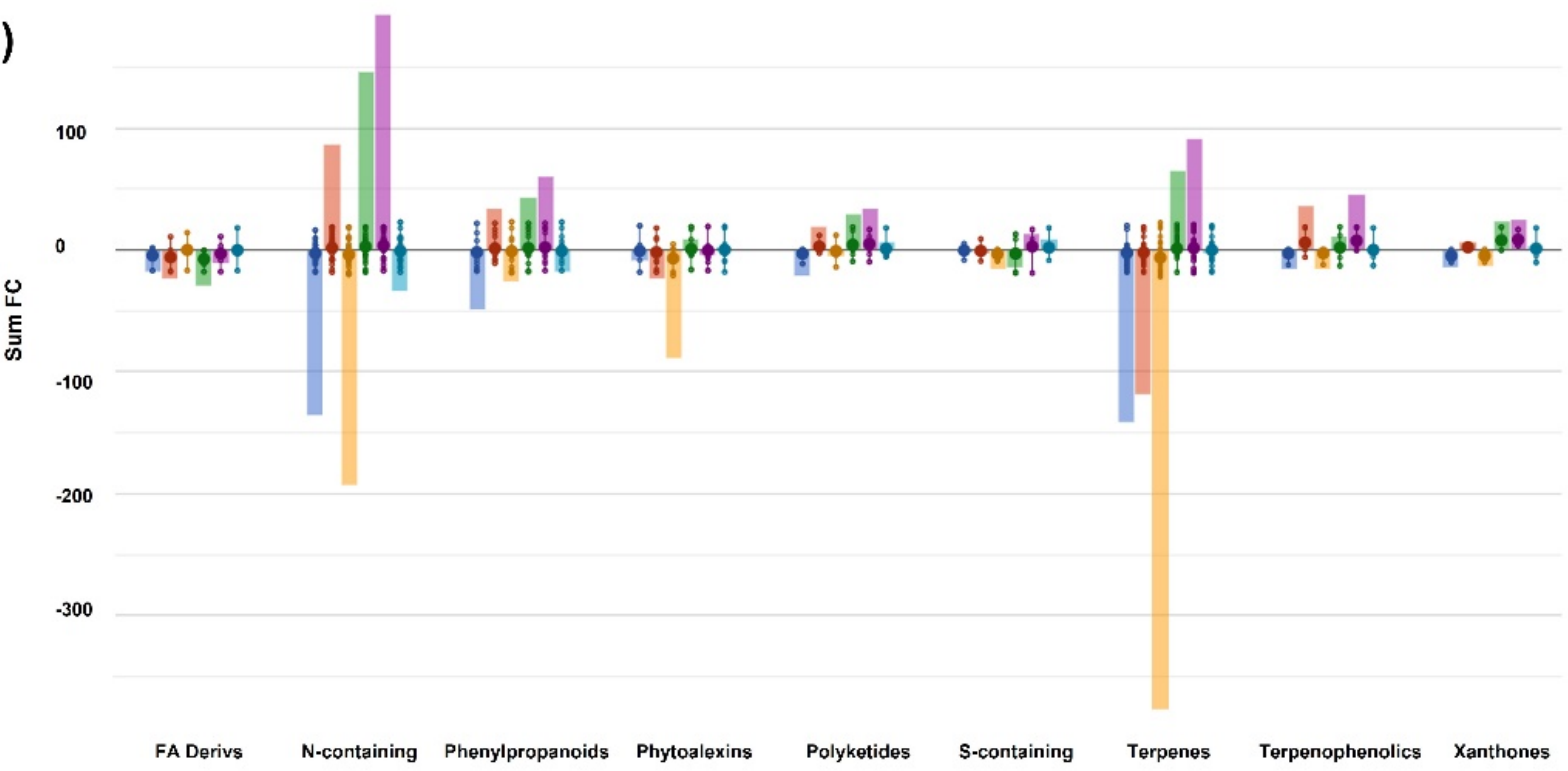

Figure 4. Summary of the biosynthetic pathways (a) and secondary metabolism (b) processes affected by protein hydrolysates (PHs) applications. The dataset produced through UHPLC-ESI/QTOF-MS was subjected to volcano plot analysis $(p<0.01$, fold-change $>3$ ) and all the differential metabolites elaborated with the PlantCyc Pathway Tool (https:/ / www.plantcyc.org, accessed on 24 March 2020). Five biological replicates were analysed for each treatment. Indole-3-acetic acid $1 \mathrm{mM}$ (IAA) was used as positive control. The $x$-axis represents each set of subcategories while the $y$-axis corresponds to the cumulative fold-change that is depicted by the height of the bar. Each dot represents the individual $\log$ FC of a single compound. The large dots are the average (mean) of all data values for metabolites within the same subcategory. Nucleo: nucleoside and nucleotide biosynthesis; FA/Lipids Syn: fatty acid and lipid biosynthesis; Amine Syn: amine and polyamine biosynthesis; Carbohyd: carbohydrate biosynthesis; Secondary metab: secondary metabolite biosynthesis; Cofactors: cofactor, prosthetic group, electron carrier, and vitamin biosynthesis; Other: other biosynthesis. FA Derivs: fatty acid derivative biosynthesis; $\mathrm{N}$-containing: $\mathrm{N}$-containing secondary metabolites; S-containing: S-containing secondary metabolites. 
Table 1. The phytohormones modulated by the different protein hydrolysates in leaves of tomato cuttings, as provided by untargeted metabolomics. Compounds are grouped into classes and are provided with individual log fold-change values (Log FC), compared to untreated control.

\begin{tabular}{|c|c|c|c|c|c|c|c|}
\hline \multirow[b]{2}{*}{ Class } & \multirow[b]{2}{*}{ Compound } & \multicolumn{6}{|c|}{$\log$ FC } \\
\hline & & IAA & PH 2 & PH 3 & PH 4 & PH 6 & PH 10 \\
\hline \multirow[t]{3}{*}{ Abscisic Acid } & $\begin{array}{l}\text { (3S,5R,6R)-3,5-Dihydroxy-6,7-Didehydro-5,6- } \\
\text { Dihydro-12'-Apo-B-Caroten-12'-Al }\end{array}$ & -8.76 & -0.36 & -8.64 & -0.97 & -8.98 & -8.83 \\
\hline & Violaxanthin & 0.03 & 0.49 & 0.68 & -17.83 & -18.68 & -0.60 \\
\hline & Dihydroxyphaseic Acid & -8.88 & 8.30 & -8.72 & 8.71 & 8.89 & -8.96 \\
\hline \multirow[t]{8}{*}{ Auxin } & (Indol-3-Yl)Acetamide & 3.38 & 3.65 & 3.34 & 3.52 & 3.65 & -14.26 \\
\hline & N2-Hydroxy-L-Tryptophan & 3.95 & -16.42 & 4.75 & -16.38 & -16.72 & 4.82 \\
\hline & Methyl (Indol-3-Yl)Acetate & -10.34 & 10.53 & -10.23 & 10.38 & 8.49 & -10.47 \\
\hline & 2-oxoindole-3-acetyl- $\beta$-D-glucose (OxIAA-Glc) & -8.69 & -8.84 & 9.79 & -9.09 & -9.12 & 9.57 \\
\hline & (indol-3-yl)acetyl-L-phenylalanine (IAA-Phe) & 14.97 & -4.81 & 15.06 & -5.08 & -5.11 & 14.76 \\
\hline & N- $\beta$-D-glucosyl-(indol-3-yl)acetate (IAA-N-Glc) & -3.28 & -3.62 & -3.15 & -3.8 & -3.84 & 0.18 \\
\hline & (indol-3-yl)acetyl-L-glutamine (IAA-Gln) & 0.22 & 0.03 & 0.36 & -3.26 & -2.81 & 0.04 \\
\hline & (indol-3-yl)acetyl-L-valine (IAA-Val) & 0.34 & 21.24 & 0.47 & 16.84 & 16.94 & 0.15 \\
\hline \multirow[t]{3}{*}{ Brassinosteroid } & $(22 \alpha)$-Hydroxy-Campesterol & & 8.52 & 0.04 & 24.25 & 23.80 & \\
\hline & (22S,24R)-22-Hydroxy- $5 \alpha$-Ergostan-3-One & 0.34 & 0.04 & 0.47 & 20.89 & 20.92 & 0.15 \\
\hline & 6-Deoxocathasterone & -10.97 & -11.07 & -10.64 & -8.04 & -8.00 & -10.97 \\
\hline \multirow[t]{3}{*}{ Cytokinin } & Dihydrozeatin-9-N-Glucoside & -7.20 & 0.09 & -1.75 & 0.11 & 0.33 & -2.90 \\
\hline & Cis-Zeatin-9-N-Glucoside & -8.18 & -18.28 & -5.49 & 0.06 & -18.61 & -10.50 \\
\hline & Lupinate & -5.43 & 2.88 & 12.20 & -5.98 & 2.67 & -5.55 \\
\hline Ethylene & 1-Aminocyclopropane-1-Carboxylate & 1.73 & -0.18 & 2.54 & -0.20 & -0.07 & 1.68 \\
\hline \multirow{12}{*}{$\begin{array}{l}\text { Gibberellin and } \\
\text { Gibberellin } \\
\text { Precursor }\end{array}$} & & & & & & & \\
\hline & Gibberellin $\mathrm{A}_{38}$ & -0.15 & -2.76 & -16.85 & 0.94 & 1.10 & -17.23 \\
\hline & Gibberellin $\mathrm{A}_{24}$ & -9.55 & -0.95 & -0.21 & -0.36 & -1.30 & -6.49 \\
\hline & Gibberellin $\mathrm{A}_{6}$ & -10.41 & -4.52 & -17.27 & -17.96 & -17.98 & -0.46 \\
\hline & Gibberellin $\mathrm{A}_{12}$-Aldehyde & 19.96 & -0.02 & 0.36 & -0.36 & 19.75 & 19.74 \\
\hline & Ent-7 $\alpha$-Hydroxykaur-16-En-19-Oate & -12.36 & -12.56 & -12.19 & 6.96 & 2.10 & 5.93 \\
\hline & gibberellin A8-catabolite & 1.31 & -11.52 & -2.44 & -11.45 & -11.72 & 2.60 \\
\hline & gibberellin A44 (closed lactone form) (GA44) & 0.48 & 0.12 & 0.55 & 5.95 & -0.16 & -0.11 \\
\hline & methyl gibberellin A4 (GA4) & -3.17 & 3.36 & -3.04 & 13.92 & 13.95 & -3.36 \\
\hline & 16,17-dihydro-16 $\alpha, 17$-dihydroxy gibberellin A12 & 0.65 & 1.05 & 2.50 & 0.11 & 0.18 & -0.37 \\
\hline & 16,17-dihydro- $16 \alpha, 17$-dihydroxy gibberellin A4 & -18.42 & -18.50 & 1.15 & -18.42 & -18.42 & \\
\hline & Ent-7 $\alpha$-Hydroxykaur-16-En-19-Oate & -12.36 & -12.56 & -12.19 & 6.96 & 2.1 & 5.93 \\
\hline \multirow[t]{5}{*}{ Jasmonate } & 1-Aminocyclopropane-1-Carboxylate & 1.73 & -0.18 & 2.54 & -0.2 & -0.07 & 1.68 \\
\hline & L-Phenylalanine & -4.40 & 4.58 & -4.27 & 18.52 & 16.52 & -4.60 \\
\hline & $\begin{array}{l}\text { (9Z,13S,15Z)-12,13-Epoxyoctadeca-9,11,15- } \\
\text { Trienoate }\end{array}$ & -16.76 & -17.05 & -16.64 & -11.57 & -8.7 & -16.82 \\
\hline & Coenzyme A & 0.34 & 0.04 & 0.47 & -0.21 & 3.38 & 18.28 \\
\hline & (+)-7-Epi-Jasmonate & -3.21 & 10.71 & 14.41 & -0.43 & 10.99 & -3.45 \\
\hline $\begin{array}{l}\text { Juvenile } \\
\text { hormone III }\end{array}$ & $(2 \mathrm{E}, 6 \mathrm{E})$-Farnesoate & -17.69 & -17.94 & -17.56 & -18.22 & -18.27 & -17.89 \\
\hline
\end{tabular}

\section{Discussion}

Biostimulants based on protein hydrolysates were shown to have positive effects on crop performance, promoting the accumulation of biomass even in adverse environmental conditions [10]. In this sense, it has been recently demonstrated that $\mathrm{PH}$ could enhance the ability of tomato and cucumber plants to acquire essential nutrients (i.e., iron) when subjected to abiotic stresses [38]. Nevertheless, the molecular aspects underpinning the action of PHs in plants are still elusive. We have recently demonstrated that the foliar treatment of tomato plants with PHs stimulated the prompt rooting of cuttings with a dramatic metabolomic reprogramming at the root level, with strong modulation of metabolites involved in hormones biosynthesis [21], further suggesting a hormone-like action in the $\mathrm{PH}$ activity.

In the present work, we compared the effects of five plants-derived PHs at a concentration of $8 \mathrm{~g} \mathrm{~L}^{-1}$ with those induced by treatments carried out with only water (negative control) and indol-3-acetic acid (IAA) at three different concentrations (positive controls) 
on (i) the rooting of tomato cuttings, (ii) the modulation of selected genes and (iii) the metabolome of tomato leaves. The treatments with PHs, as also previously observed [21], were effective in promoting the development of the root system in tomato cuttings to the same or, in some cases, to a greater extent, compared to IAA (Figure 1). In order to understand whether the treatments with PHs at the leaf level could be perceived by plants as exogenous auxin stimulation, the transcriptional modulation of IAA responsive genes, namely SIIAA2 and SIIAA9, was investigated. Both genes belong to the auxin/indole3-acetic acid (Aux/IAA) families of transcription factors and have been shown to be instrumental in auxin-dependent transcriptional regulation [39] and to be transcriptionally activated by external application of IAA in tomato seedlings [37]. Upon PH and IAA treatments, SIIAA9 displayed an upregulation compared to negative controls, except in the case of PH4 treatment, suggesting that molecular effector(s) present in the PHs mixture might mimic the activity of the phytohormone auxin. On the other hand, SIIAA2 did not show a modulation following the treatments, except for the case of PH4 and PH6. It is important to point out that the responsiveness of Aux/IAA genes to IAA can be highly variable from gene to gene. In fact, depending on the gene and applied IAA concentration, the transcriptional activation might range from strong and quick upregulation [40] to a slight sinking in the mRNA levels [41]. In this context, SIIAA2 has been demonstrated to feature a quick responsiveness to external auxin application, whereas SIIAA9 displayed slower kinetics in the response [37], which could also support our observations carried out in seedling at 7 days after the treatments. In addition, the different origin of the PHs might also mirror a slightly different composition in terms of free amino acids and small peptides, that might underpin the observed differences in the responses.

Metabolomics was used to shed light on the metabolic pathways modulated by the five PHs tested on leaves of tomato cuttings. Wounding interrupted the flux of substances between roots and leaves, which inevitably triggered a developmental reprogramming into the isolated shoot to involve several molecular, hormonal and metabolic factors [42]. We observed a clear and distinctive modulation of plant metabolism in response to all biostimulant applications, concerning secondary pathways as well as metabolites linked to phytohormone synthesis and inactivation, which may be the basis of the morphological adaptations that we observed in roots. Although $\mathrm{PH}$ application provided a general promotion on root growth without any significant difference across $\mathrm{PH}$ treatments, two main signatures described the leaf metabolome of tomato plants, one in response to $\mathrm{PH} 3$ and PH10 behaving more likely positive controls (IAA $1 \mathrm{mM}$ ) (Figure 3). A second metabolomic cluster was observed in response to PH4 and PH6, whereas PH2-treated samples displayed an intermediate behaviour (Figure 3). The similarity in response to PH4 and PH6 was previously described, even though an overall depletion of secondary metabolites was observed in the roots of tomato cuttings [21]. On the contrary, a generalized accumulation of secondary metabolites was evidenced in the leaves treated with these biostimulants (Figure 4a), indicating a tissue-specific regulation on plant metabolism.

The PH-specific modulation involved phytohormone pathways (Table 1), further corroborating an effect on hormone levels of these biostimulants [21]. We found peculiar changes in brassinosteroids (BRs), cytokinins (CKs) and jasmonate (JA), as well as in auxin and ethylene metabolism. The close interaction of all these phytohormones in the developmental processes of plants has been largely demonstrated [43]. BRs are a class of polyhydroxy steroidal hormones with many roles in plant growth and development. Noteworthy is that the differential supplementation of BRs can impact root growth [44]. The BRs pathway was suppressed in positive controls and all PH-treated plants with the exception of PH4 and PH6, which could explain a concentration-dependent regulation by BRs in controlling the root meristem size, as previously reported in Arabidopsis [45]. Moreover, BRs can regulate auxin-responsive genes involved in root development [46]. Plants treated with PHs under-accumulated N-glycosylated forms of CKs, particularly cis-zeatin. N-glycosylation is an enzymatic reaction that is thought to inactivate CKs. Ciszeatin can affect plant growth and development at different stages and tissues in plants, 
including root development [47]. Guan and colleagues (2019) demonstrated that stems of tomato cuttings treated with indole-3-acetate (IAA) showed a peak of zeatin at 5 days after treatments to coincide with adventitious roots extension, demonstrating the role of $\mathrm{CKs}$ in root elongation during this phase [48]. The authors suggested that CKs positively promoted adventitious roots with a complementary role to auxin. Finally, a precursor of JA accumulated in response to $\mathrm{PH} 2, \mathrm{PH} 3$ and $\mathrm{PH} 6$, whereas the precursor of ethylene 1-aminocyclo-propane (ACC) slightly accumulated in PH3- and PH10-treated plants. Ethylene can inhibit root growth, interplaying with auxin synthesis and transport by regulating the expression of several auxin carriers [49]. JA is also known to be involved in root development with proven negative effects on adventitious root formation in Arabidopsis [50]. Indeed, the authors demonstrated a clear crosstalk between auxin and JA aimed at fine-tuning the pools of free IAA and JA during adventitious rooting. This regulation is achieved by the transcriptional modulation of genes belonging to the Gretchen Hagen 3 (GH3) family, which are responsible for IAA conjugation. More recent work demonstrated that adventitious root initiation depends on a regulatory model that involves TIR1/AFB, Aux/IAA proteins (IAA6, IAA9, and IAA17), and ARFs, which can modulate the homeostasis of JA [51].

The complex modulation of phytohormone crosstalk pointed out a very PH-specific mode of action. In this context, the spatiotemporal plasticity of auxin metabolism sustains the signalling network within the whole plants and is determined throughout de novo synthesis, conjugation, degradation and transport [52]. Biostimulants caused the modulation of metabolites linked to the maintenance of the highly dynamic auxin pool. The homeostasis of the auxin pool can be regulated through (1) biosynthesis, (2) interconversion, (3) storage and (4) transport of auxin. Interestingly, all PHs significantly modulated compounds which can be related to all these levels of regulation. After wounding, an early accumulation of IAA in shoots self-regulates basipetal auxin transport to the root tips [14]. At 7 days after treatment, IAA biosynthesis was still active, since precursors of IAA (i.e., indole-3-acetamide, $\mathrm{N}^{2}$-hydroxy-L-tryptophane) accumulated in shoots in response to all treatments with a comparable extent to the positive controls. On the other hand, several IAA-conjugates were differentially modulated. IAA-conjugates can serve either as precursors for the degradation pathways or as a storage form of auxins to allow a quick release of IAA as needed [53]. The irreversible inactivation of IAA through oxidation is the major route for IAA catabolism in plants, which helps to maintain endogenous auxin homeostasis [54]. The synthesis of 2-oxoindole-3-acetyl- $\beta$-D-glucose (OxIAA-Glc) via glycosylation of OxIAA was reduced about 10-fold, except for PH3 and PH10-treated plants in which OxIAA-Glc accumulated. IAA catabolism has been proposed to act redundantly, along with IAA-conjugating enzymes of the GH3 family, to maintain auxin levels [55]. It has been proposed that OxIAA could have a role in controlling basal levels of IAA, whereas GH3-mediated conjugation is more crucial when a rapid reduction of IAA is needed in response to developmental and external stimuli [56]. IAA-amide conjugates are synthesized by members of the GH3 family [52], of which transcription is regulated by auxin level and auxin-like herbicides [57,58]. The role of many different IAA-amino acid conjugates is well documented [53]. Some IAA-amide conjugates (IAA-Ala, IAA-Leu, IAA-Phe, IAA-Val) can affect the free IAA pool after their hydrolyzation to the active IAA form, thus altering root development $[59,60]$. The role of IAA-conjugates in auxin regulation is still not fully clear, but their biosynthesis has been demonstrated by some members of the GH3 family [61]. IAA-Phe can induce developmental responses in both the shoot and root of Arabidopsis after its hydrolyzation by amidohydrolases from the ILR1-like family [60]. MeIAA is an inactive auxin, a more easily transportable form of IAA through cell membranes, to reach distant targets such as roots, where local methyl indole-3-acetate methyltransferase can convert it back to the active form [62]. Interestingly, PH3 and PH10 over and under-accumulated IAA-Phe and MeIAA respectively, whereas PH4 and PH6 caused the exact opposite. 
Concerning the elicitation of secondary metabolism, nitrogen-containing compounds, mainly alkaloids and glucosinolates, as well as phenylpropanoids and terpenes, were modulated (Figure 4b). As a general trend, PH3 and PH10 caused an overall depletion of secondary compounds, whereas PH4 and PH6 behaved the opposite way. All these classes of metabolites are related to nitrogen metabolism, underpinning a potential PH-specific modulation of nutrient uptake and use efficiency [63]. Other than nitrogen storage, several of these compounds are also involved in plant defence against both biotic and abiotic stressors, as well as in plant growth, development and reproduction [64]. Interestingly, the phenylpropanoid pathway has been linked to auxin and CKs in regulating the growth of Arabidopsis plants [65]. The authors concluded that the accumulation of metabolites upstream the cinnamate-4-hydroxylase, an early step in phenylpropanoid metabolism, could tune auxin-mediated plant growth.

\section{Conclusions}

Vegetal-derived PHs can effectively promote crop performance in terms of growth, development, and stress resistance [66]. The proven feature of PHs to impact phytohormone homeostasis might suggest that specific components (i.e., amino acids and/or peptides) may mimic the action of signalling molecules of plants, most likely peptides $[17,67]$. In this respect, we speculate that $\mathrm{PH}$-induced modulation of plant metabolism could result from a complex interplay between effector(s), receptors, and second messengers, which need to be further investigated. Nonetheless, the $\mathrm{PH}$-specific modulations produced on plant metabolism highlight the potential versatility of this class of biostimulants.

Supplementary Materials: The following are available online at https://www.mdpi.com/article/10 .3390/agronomy11081524/s1. Figure S1: Score plot of OPLS-DA on leaves metabolomic analysis. Table S1: Sequence of gene-specific oligonucleotides used for Real Time RT-PCR analyses. Table S2: Complete list of compounds obtained through metabolomic analysis. Table S3: List of differentially represented metabolites according to Volcano Plot analysis.

Author Contributions: V.B., Y.P., L.L. wrote the first draft of the manuscript. A.V.C., Y.R., M.C. made the phenotyping measurements. V.B., B.M.-M., V.B., L.L. performed the metabolomics analysis. Y.P. performed gene expression analysis. All authors were involved in data analysis, data interpretation, and revising the manuscript. Y.R., L.L. and G.C. coordinated the whole project, provided the intellectual input, set up the experiments, and corrected the final version of the manuscript. All authors have read and agreed to the published version of the manuscript.

Funding: This research received no external funding.

Data Availability Statement: The dataset generated for this study are available as Supplementary Materials.

Acknowledgments: This work was carried out in the framework of the project 'PHOBOS-Use of Protein-HydrOlysates as BiOstimulants of vegetable cropS: elucidating their mode of action and optimizing their effectiveness through a multidisciplinary approach' funded within the PRIN call by the Italian Ministry of Education, University and Research (MIUR) (prot. n. 2017FYBLPP). Moreover, the work benefited from a predoctoral contract for the training and improvement abroad of research staff (Begoña Miras-Moreno) financed by the Consejería de Empleo, Universidades, Em-presa y Medio Ambiente of the CARM, through the Fundación Séneca-Agencia de Ciencia y Tecnología de la Región de Murcia. This work is part of the Ph.D. thesis of Angela Valentina Ceccarelli at Tuscia University, and it was partially funded by MIUR in the frame of the initiative "Departments of excellence", Law 232/2016. The authors also thank the "Romeo ed Enrica Invernizzi" Foundation, Milan (Italy) for the kind support to the metabolomics facility, and Helene Reynaud of Hello Nature Co Ltd. for the support in the development of vegetal-derived protein hydrolysates.

Conflicts of Interest: The authors declare no conflict of interest. 


\section{References}

1. Calicioglu, O.; Flammini, A.; Bracco, S.; Bellù, L.; Sims, R. The future challenges of food and agriculture: An integrated analysis of trends and solutions. Sustainability 2019, 11, 222. [CrossRef]

2. Taiz, L. Agriculture, plant physiology, and human population growth: Past, present, and future. Theor. Exp. Plant Physiol. 2013, 25, 167-181. [CrossRef]

3. Koppelaar, R.H.E.M.; Weikard, H.P. Assessing phosphate rock depletion and phosphorus recycling options. Glob. Environ. Chang. 2013, 23, 1454-1466. [CrossRef]

4. Prăvălie, R.; Patriche, C.; Borrelli, P.; Panagos, P.; Roșca, B.; Dumitraşcu, M.; Nita, I.A.; Săvulescu, I.; Birsan, M.V.; Bandoc, G. Arable lands under the pressure of multiple land degradation processes. A global perspective. Environ. Res. 2021, $194,110697$. [CrossRef]

5. Caradonia, F.; Battaglia, V.; Righi, L.; Pascali, G.; La Torre, A. Plant biostimulant regulatory framework: Prospects in Europe and current situation at international level. J. Plant Growth Regul. 2019, 38, 438-448. [CrossRef]

6. Rouphael, Y.; Colla, G. Editorial: Biostimulants in Agriculture. Front. Plant Sci. 2020, 11, 40. [CrossRef] [PubMed]

7. Kauffman, G.L.; Kneivel, D.P.; Watschke, T.L. Effects of a biostimulant on the heat tolerance associated with photosynthetic capacity, membrane thermostability, and polyphenol production of perennial ryegrass. Crop Sci. 2007, 47, 261-267. [CrossRef]

8. Jardin, P.; Xu, L.; Geelen, D. Agricultural Functions and Action Mechanisms of Plant Biostimulants (PBs). In The Chemical Biology of Plant Biostimulants; Wiley: Hoboken, NJ, USA, 2020; pp. 1-30.

9. Yakhin, O.I.; Lubyanov, A.A.; Yakhin, I.A.; Brown, P.H. Biostimulants in plant science: A global perspective. Front. Plant Sci. 2017, 7, 2049. [CrossRef]

10. Colla, G.; Nardi, S.; Cardarelli, M.; Ertani, A.; Lucini, L.; Canaguier, R.; Rouphael, Y. Protein hydrolysates as biostimulants in horticulture. Sci. Hortic. 2015, 196, 28-38. [CrossRef]

11. Colantoni, A.; Recchia, L.; Bernabei, G.; Cardarelli, M.; Rouphael, Y.; Colla, G. Analyzing the environmental impact of chemicallyproduced protein hydrolysate from leather waste vs. Enzymatically-produced protein hydrolysate from legume grains. Agriculture 2017, 7, 62. [CrossRef]

12. Colla, G.; Rouphael, Y.; Canaguier, R.; Svecova, E.; Cardarelli, M. Biostimulant action of a plant-derived protein hydrolysate produced through enzymatic hydrolysis. Front. Plant Sci. 2014, 5, 448. [CrossRef]

13. Ertani, A.; Pizzeghello, D.; Francioso, O.; Tinti, A.; Nardi, S. Biological activity of vegetal extracts containing phenols on plant metabolism. Molecules 2016, 21, 205. [CrossRef]

14. Michniewicz, M.; Brewer, P.B.; Friml, J. Polar auxin transport and asymmetric auxin distribution. Arab. Book 2007, 5, e0108. [CrossRef]

15. Casanova-Sáez, R.; Mateo-Bonmatí, E.; Ljung, K. Auxin Metabolism in Plants. Cold Spring Harb. Perspect. Biol. 2021, 13, a039867. [CrossRef]

16. Petrozza, A.; Santaniello, A.; Summerer, S.; Di Tommaso, G.; Di Tommaso, D.; Paparelli, E.; Piaggesi, A.; Perata, P.; Cellini, F. Physiological responses to Megafol ${ }^{\circledR}$ treatments in tomato plants under drought stress: A phenomic and molecular approach. Sci. Hortic. 2014, 174, 185-192. [CrossRef]

17. Lucini, L.; Miras-Moreno, B.; Rouphael, Y.; Cardarelli, M.; Colla, G. Combining molecular weight fractionation and metabolomics to elucidate the bioactivity of vegetal protein hydrolysates in tomato plants. Front. Plant Sci. 2020, 11. [CrossRef]

18. Evans, M.L.; Ishikawa, H.; Estelle, M.A. Responses of Arabidopsis roots to auxin studied with high temporal resolution: Comparison of wild type and auxin-response mutants. Planta 1994, 194, 215-222. [CrossRef]

19. Muday, G.K.; Lomax, T.L.; Rayle, D.L. Characterization of the growth and auxin physiology of roots of the tomato mutant, diageotropica. Planta 1995, 195, 548-553. [CrossRef] [PubMed]

20. Ertani, A.; Cavani, L.; Pizzeghello, D.; Brandellero, E.; Altissimo, A.; Ciavatta, C.; Nardi, S. Biostimulant activity of two protein hydrolyzates in the growth and nitrogen metabolism of maize seedlings. J. Plant Nutr. Soil Sci. 2009, 172, 237-244. [CrossRef]

21. Ceccarelli, A.V.; Miras-Moreno, B.; Buffagni, V.; Senizza, B.; Pii, Y.; Cardarelli, M.; Rouphael, Y.; Colla, G.; Lucini, L. Foliar application of different vegetal-derived protein hydrolysates distinctively modulates tomato root development and metabolism. Plants 2021, 10, 326. [CrossRef] [PubMed]

22. Kim, H.J.; Ku, K.M.; Choi, S.; Cardarelli, M. Vegetal-derived biostimulant enhances adventitious rooting in cuttings of basil, tomato, and chrysanthemum via brassinosteroid-mediated processes. Agronomy 2019, 9, 74. [CrossRef]

23. Pii, Y.; Alessandrini, M.; Dall'Osto, L.; Guardini, K.; Prinsi, B.; Espen, L.; Zamboni, A.; Varanini, Z. Time-resolved investigation of molecular components involved in the induction of $\mathrm{NO}_{3}{ }^{-}$high affinity transport system in maize roots. Front. Plant Sci. 2016, 7, 1657. [CrossRef]

24. Pfaffl, M.W.; Horgan, G.W.; Dempfle, L. Relative expression software tool (RESTC) for group-wise comparison and statistical analysis of relative expression results in real-time PCR. Nucleic Acids Res. 2002, 30, e36. [CrossRef] [PubMed]

25. Pfaffl, M.W. A new mathematical model for relative quantification in real-time RT-PCR. Nucleic Acids Res. 2001, 29, e45. [CrossRef] [PubMed]

26. Salehi, H.; Chehregani, A.; Lucini, L.; Majd, A.; Gholami, M. Morphological, proteomic and metabolomic insight into the effect of cerium dioxide nanoparticles to Phaseolus vulgaris L. under soil or foliar application. Sci. Total Environ. 2018, 616-617, 1540-1551. [CrossRef] [PubMed] 
27. Rouphael, Y.; Lucini, L.; Miras-Moreno, B.; Colla, G.; Bonini, P.; Cardarelli, M. Metabolomic responses of maize shoots and roots elicited by combinatorial seed treatments with microbial and non-microbial biostimulants. Front. Microbiol. 2020, 11, 664. [CrossRef]

28. Miras-Moreno, B.; Corrado, G.; Zhang, L.; Senizza, B.; Righetti, L.; Bruni, R.; El-Nakhel, C.; Sifola, M.I.; Pannico, A.; De Pascale, S.; et al. The metabolic reprogramming induced by sub-optimal nutritional and light inputs in soilless cultivated green and red butterhead lettuce. Int. J. Mol. Sci. 2020, 21, 6381. [CrossRef]

29. Salek, R.M.; Steinbeck, C.; Viant, M.R.; Goodacre, R.; Dunn, W.B. The role of reporting standards for metabolite annotation and identification in metabolomic studies. Gigascience 2013, 2, 13. [CrossRef]

30. Tsugawa, H.; Cajka, T.; Kind, T.; Ma, Y.; Higgins, B.; Ikeda, K.; Kanazawa, M.; Vandergheynst, J.; Fiehn, O.; Arita, M. MS-DIAL: Data-independent MS/MS deconvolution for comprehensive metabolome analysis. Nat. Methods 2015, 12, 523-526. [CrossRef]

31. Tsugawa, H.; Kind, T.; Nakabayashi, R.; Yukihira, D.; Tanaka, W.; Cajka, T.; Saito, K.; Fiehn, O.; Arita, M. Hydrogen Rearrangement Rules: Computational MS/MS Fragmentation and Structure Elucidation Using MS-FINDER Software. Anal. Chem. 2016, 88, 7946-7958. [CrossRef]

32. Wickham, H. Ggplot2: Elegant Graphics for Data Analysis; Springer, 2016; ISBN 3319242776. Available online: https://www. springer.com/jp/book/9783319242750 (accessed on 12 June 2020).

33. de Mendiburu, F. Package 'agricolae'. R Packag. Version 2019, 1-2.

34. Tang, Y.; Horikoshi, M.; Li, W. Ggfortify: Unified interface to visualize statistical results of popular r packages. $R J$. 2016, 8 , 478-489. [CrossRef]

35. Caspi, R.; Dreher, K.; Karp, P.D. The challenge of constructing, classifying, and representing metabolic pathways. FEMS Microbiol. Lett. 2013, 345, 85-93. [CrossRef]

36. Karp, P.D.; Paley, S.M.; Krummenacker, M.; Latendresse, M.; Dale, J.M.; Lee, T.J.; Kaipa, P.; Gilham, F.; Spaulding, A.; Popescu, L.; et al. Pathway Tools version 13.0: Integrated software for pathway/genome informatics and systems biology. Brief. Bioinform. 2010, 11, 40-79. [CrossRef]

37. Wang, H.; Jones, B.; Li, Z.; Frasse, P.; Delalande, C.; Regad, F.; Chaabouni, S.; Latché, A.; Pech, J.-C.; Bouzayen, M. The Tomato Aux/IAA Transcription Factor IAA9 Is Involved in Fruit Development and Leaf Morphogenesis. Plant Cell 2005, 17, 2676 LP-2692. [CrossRef]

38. Celletti, S.; Astolfi, S.; Guglielmo, N.; Colla, G.; Cesco, S.; Mimmo, T. Evaluation of a legume-derived protein hydrolysate to mitigate iron deficiency in plants. Agronomy 2020, 10, 1942. [CrossRef]

39. Luo, J.; Zhou, J.-J.; Zhang, J.-Z. Aux/IAA gene family in plants: Molecular structure, regulation, and function. Int. J. Mol. Sci. 2018, 19, 259. [CrossRef]

40. Abel, S.; Nguyen, M.D.; Theologis, A. The PS-IAA4/5-like family of early auxin-inducible mRNAs in Arabidopsis thaliana. J. Mol. Biol. 1995, 251, 533-549. [CrossRef] [PubMed]

41. Rogg, L.E.; Lasswell, J.; Bartel, B. A gain-of-function mutation in IAA28 suppresses lateral root development. Plant Cell 2001, 13, 465-480. [CrossRef]

42. Druege, U.; Hilo, A.; Pérez-Pérez, J.M.; Klopotek, Y.; Acosta, M.; Shahinnia, F.; Zerche, S.; Franken, P.; Hajirezaei, M.R. Molecular and physiological control of adventitious rooting in cuttings: Phytohormone action meets resource allocation. Ann. Bot. 2019, 123, 929-949. [CrossRef] [PubMed]

43. Wang, Y.H.; Irving, H.R. Developing a model of plant hormone interactions. Plant Signal. Behav. 2011, 6, 494-500. [CrossRef] [PubMed]

44. Wei, Z.; Li, J. Brassinosteroids regulate root growth, development, and symbiosis. Mol. Plant 2016, 9, 86-100. [CrossRef]

45. González-García, M.P.; Vilarrasa-Blasi, J.; Zhiponova, M.; Divol, F.; Mora-García, S.; Russinova, E.; Caño-Delgado, A.I. Brassinosteroids control meristem size by promoting cell cycle progression in Arabidopsis roots. Development 2011, 138, 849-859. [CrossRef] [PubMed]

46. Mouchel, C.F.; Osmont, K.S.; Hardtke, C.S. BRX mediates feedback between brassinosteroid levels and auxin signalling in root growth. Nature 2006, 443, 458-461. [CrossRef] [PubMed]

47. Schäfer, M.; Brütting, C.; Meza-Canales, I.D.; Großkinsky, D.K.; Vankova, R.; Baldwin, I.T.; Meldau, S. The role of cis-zeatin-type cytokinins in plant growth regulation and mediating responses to environmental interactions. J. Exp. Bot. 2015, 66, 4873-4884. [CrossRef] [PubMed]

48. Guan, L.; Tayengwa, R.; Cheng, Z.M.; Peer, W.A.; Murphy, A.S.; Zhao, M. Auxin regulates adventitious root formation in tomato cuttings. BMC Plant Biol. 2019, 19, 1-16. [CrossRef]

49. Xu, P.; Zhao, P.X.; Cai, X.T.; Mao, J.L.; Miao, Z.Q.; Xiang, C. Bin Integration of Jasmonic Acid and Ethylene Into auxin signaling in root development. Front. Plant Sci. 2020, 11, 271. [CrossRef]

50. Gutierrez, L.; Mongelard, G.; Floková, K.; Păcurar, D.I.; Novák, O.; Staswick, P.; Kowalczyk, M.; Păcurar, M.; Demailly, H.; Geiss, G.; et al. Auxin controls Arabidopsis adventitious root initiation by regulating jasmonic acid homeostasis. Plant Cell 2012, 24, 2515-2527. [CrossRef]

51. Lakehal, A.; Chaabouni, S.; Cavel, E.; Le Hir, R.; Ranjan, A.; Raneshan, Z.; Novák, O.; Păcurar, D.I.; Perrone, I.; Jobert, F.; et al. A molecular framework for the control of adventitious rooting by TIR1/AFB2-Aux/IAA-dependent auxin signaling in Arabidopsis. Mol. Plant 2019, 12, 1499-1514. [CrossRef] 
52. Ruiz Rosquete, M.; Barbez, E.; Kleine-Vehn, J. Cellular auxin homeostasis: Gatekeeping is housekeeping. Mol. Plant 2012, 5, 772-786. [CrossRef]

53. Ludwig-Müller, J. Auxin conjugates: Their role for plant development and in the evolution of land plants. J. Exp. Bot. 2011, 62, 1757-1773. [CrossRef] [PubMed]

54. Zhang, J.; Peer, W.A. Auxin homeostasis: The DAO of catabolism. J. Exp. Bot. 2017, 68, 3145-3154. [CrossRef]

55. Porco, S.; Pěnčík, A.; Rasheda, A.; Vo, U.; Casanova-Sáez, R.; Bishopp, A.; Golebiowska, A.; Bhosale, R.; Swarupa, R.; Swarup, K.; et al. Dioxygenase-encoding AtDAO1 gene controls IAA oxidation and homeostasis in Arabidopsis. Proc. Natl. Acad. Sci. USA 2016, 113, 11016-11021. [CrossRef]

56. Olatunji, D.; Geelen, D.; Verstraeten, I. Control of endogenous auxin levels in plant root development. Int. J. Mol. Sci. 2017, 18, 2587. [CrossRef]

57. Gee, M.A.; Hagen, G.; Guilfoyle, T.J. Tissue-specific and organ-specific expression of soybean auxin-responsive transcripts GH3 and SAURs. Plant Cell 1991, 3, 419-430. [PubMed]

58. Kelley, K.B.; Lambert, K.N.; Hager, A.G.; Riechers, D.E. Quantitative expression analysis of GH3, a gene induced by plant growth regulator herbicides in soybean. J. Agric. Food Chem. 2004, 52, 474-478. [CrossRef]

59. LeClere, S.; Tellez, R.; Rampey, R.A.; Matsuda, S.P.T.; Bartel, B. Characterization of a family of IAA-amino acid conjugate hydrolases from Arabidopsis. J. Biol. Chem. 2002, 277, 20446-20452. [CrossRef] [PubMed]

60. Rampey, R.A.; LeClere, S.; Kowalczyk, M.; Ljung, K.; Sandberg, G.; Bartel, B. A family of auxin-conjugate hydrolases that contributes to free indole-3-acetic acid levels during Arabidopsis germination. Plant Physiol. 2004, 135, 978-988. [CrossRef] [PubMed]

61. Staswick, P.E.; Serban, B.; Rowe, M.; Tiryaki, I.; Maldonado, M.T.; Maldonado, M.C.; Suza, W. Characterization of an Arabidopsis enzyme family that conjugates amino acids to indole-3-acetic acid. Plant Cell 2005, 17, 616-627. [CrossRef]

62. Yang, Y.; Xu, R.; Ma, C.J.; Vlot, A.C.; Klessig, D.F.; Pichersky, E. Inactive methyl indole-3-acetic acid ester can be hydrolyzed and activated by several esterases belonging to the AtMES esterase family of Arabidopsis. Plant Physiol. 2008, 147, 1034-1045. [CrossRef] [PubMed]

63. Colla, G.; Hoagland, L.; Ruzzi, M.; Cardarelli, M.; Bonini, P.; Canaguier, R.; Rouphael, Y. Biostimulant action of protein hydrolysates: Unraveling their effects on plant physiology and microbiome. Front. Plant Sci. 2017, 8, 2002. [CrossRef] [PubMed]

64. Böttger, A.; Vothknecht, U.; Bolle, C.; Wolf, A. Plant secondary metabolites and their general function in plants. In Lessons on Caffeine, Cannabis and Co; Springer: Cham, Switzerland, 2018; pp. 3-17.

65. Kurepa, J.; Shull, T.E.; Karunadasa, S.S.; Smalle, J.A. Modulation of auxin and cytokinin responses by early steps of the phenylpropanoid pathway. BMC Plant Biol. 2018, 18, 1-15. [CrossRef] [PubMed]

66. Lucini, L.; Rouphael, Y.; Cardarelli, M.; Bonini, P.; Baffi, C.; Colla, G. A vegetal biopolymer-based biostimulant promoted root growth in melon while triggering brassinosteroids and stress-related compounds. Front. Plant Sci. 2018, 9, 472. [CrossRef]

67. Bonini, P.; Rouphael, Y.; Miras-Moreno, B.; Lee, B.; Cardarelli, M.; Erice, G.; Cirino, V.; Lucini, L.; Colla, G. A microbialbased biostimulant enhances sweet pepper performance by metabolic reprogramming of phytohormone profile and secondary netabolism. Front. Plant Sci. 2020, 11, 1727. [CrossRef] [PubMed] 